LIAMES, Campinas, SP, v. 20, 1-20, e020016, 2020

\title{
Panorama dos estudos linguísticos no Tumucumaque
}

\author{
Antonio Almir Silva Gomes ${ }^{1}$ \\ Universidade Federal do Amapá, Brasil \\ https://orcid.org/0000-0002-1505-2087 \\ Iohana Victória Barbosa Ferreira \\ PG - Universidade Federal do Amapá, Brasil \\ https://orcid.org/0000-0003-2218-777X
}

Tumucumaque é o nome que se refere a duas áreas geográficas ao norte do Brasil, o Parque Nacional Montanhas do Tumucumaque e o Parque Indígena do Tumucumaque. O Parque Nacional Montanhas do Tumucumaque constitui-se de uma área de 3.865.188,53 hectares (ICMBIO) ${ }^{2}$ localizada em sua maioria ao norte do estado do Pará, com uma pequena extensão localizada a oeste do estado do Amapá; foi criado como tal por Decreto Federal s/n no dia 22 de agosto de 2002. O Parque Indígena do Tumucumaque, por sua vez, segundo o Instituto de Pesquisa e Formação Indígena (IEPÉ), , “...é constituído pelas Terras Indígenas Parque do Tumucumaque e Paru D’Este, situadas, em sua maior parte, no Estado do Pará, e em uma pequena faixa no Estado do Amapá”. Juntas, as Terras Indígenas Parque do Tumucumaque e Paru D'Este, segundo o IEPÉ, formam o Complexo do Tumucumaque.

\footnotetext{
${ }^{1}$ Agradecemos aos pareceristas da Revista Liames pelas valiosas contribuições feitas ao artigo. Igualmente, agradecemos ao professor Dr. Fernando Orphão de Carvalho da Universidade Federal do Amapá.

2 https://www.icmbio.gov.br/portal/unidadesdeconservacao/biomabrasileiros/amazonia/unidadesde-conservacao-amazonia/1990-parna-montanhas-do-tumucumaque

${ }^{3} \mathrm{https}$ //www.institutoiepe.org.br/area-de-atuacao/povos-indigenas/complexo-tumucumaque/
}

DOI: http://dx.doi.org/10.20396/liames.v20i0.8660797 


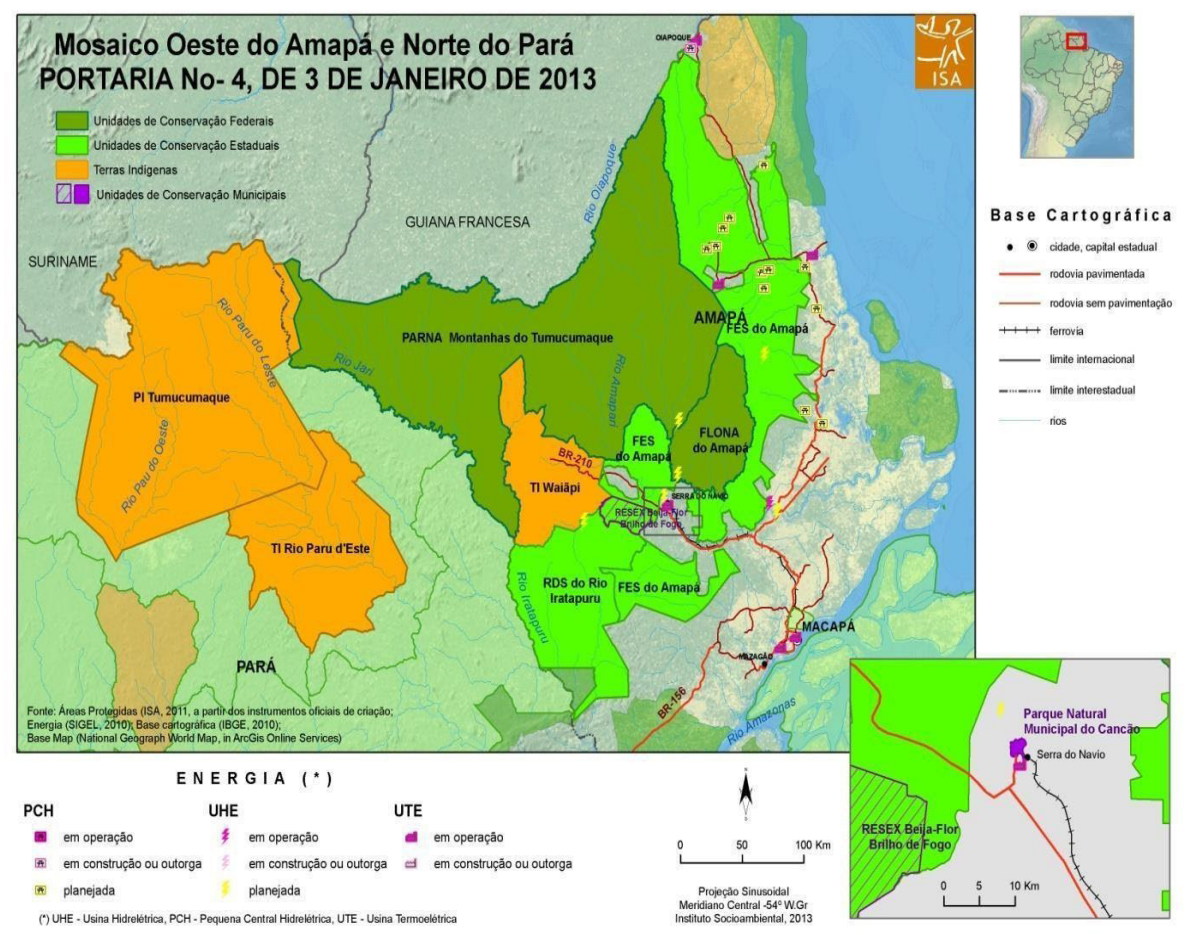

Fonte: https://www.icmbio.gov.br/portal/images/stories/mosaicos/1Mosaico_OesteAP_ NortePA_2.jpg

As terras que constituem o Complexo do Tumucumaque são o lugar onde vivem aproximadamente 2450 indivíduos pertencentes a distintos povos indígenas. Ao lado oeste (Terra Indígena Parque do Tumucumaque) são encontradas cerca de 30 aldeias com 1550 indivíduos pertencentes majoritariamente aos povos Tiriyó, Kaxuyana e Xikiyana. Ao lado leste (Terra Indígena Paru D'Este) são encontradas cerca de 21 aldeias com 900 pessoas pertencentes majoritariamente aos povos Apalaí, Wayana e Tiriyó. No geral, os indivíduos que vivem no Complexo do Tumucumaque são falantes das línguas Apalaí, Kaxuyana, Tiriyó e Wayana. A este cenário de quatro línguas juntam-se as línguas Akuriyó e Xikiyana de populações de mesmo nome que vivem atualmente entre populações Tiriyó. Na memória atual destas duas populações, tratam-se de línguas trazidas do Suriname por seus falantes. Devido ao uso predominante da língua Tiriyó pelos Akuriyó e Xikiyana, são línguas não mais transmitidas como maternas. Contudo, temos notícias, que demandam maior investigação com rigor científico, da existência de um pequeno grupo ainda falante de Xikiyana e de alguns lembrantes da língua Akuriyó, que a utilizaram até a adolescência como língua materna.

Ao observarmos as relações genéticas das seis línguas mencionadas, conforme classificação de Rodrigues (1986), um detalhe chama a atenção: todas pertencem à família 
linguística Karíb, o que nos faz compreender que o Complexo do Tumucumaque é lar de falantes de línguas Karíb.

A presença dessas línguas no Complexo do Tumucumaque, adicionada ao fato de que seus falantes interagem rotineiramente entre si em virtude da proximidade geográfica, gera inúmeros cenários de contatos linguísticos. Para além de contatos entre as línguas Karíb, esses povos estabelecem contatos com populações indígenas falantes de línguas pertencentes a outras famílias, como os Wajãpí, falantes de língua homônima (TupiGuarani) que vivem majoritariamente na Terra Indígena Wajãpí, estado do Amapá. Seja na escola da aldeia, seja ao sair de seus lugares para a cidade, os povos Karíb em questão estabelecem contatos com o Português Brasileiro, de modo que até mesmo as crianças das aldeias passam a ter contato com esta língua cada vez mais cedo. No caso dos Tiriyó, devido à relação parental com indivíduos que vivem no Suriname, tem-se a presença em seus lugares, de alguma maneira, até mesmo da língua holandesa. Os cenários em questão foram tratados por Gomes, Barbosa e Ferreira (2020) como cenários multilíngues. Do ponto de vista linguístico, temos, portanto, que Tumucumaque é nome que deve ser atrelado à família linguística Karíb, mas também a multilinguismo; Tumucumaque multilíngue!

Uma vez apresentado o cenário Karíb / Multilíngue inerente ao Complexo do Tumucumaque, nosso objetivo consiste em traçar um panorama dos estudos linguísticos realizados acerca das línguas em questão; com isso, chamar a atenção para sua natureza multilíngue, além de sistematizar informações linguísticas disponíveis. Com o conjunto de objetivos, interessa-nos, ao final, projetar distintas direções relacionadas a possibilidades de estudos linguísticos dessa área geográfica.

No panorama em questão, conforme se observará, trataremos de textos resultado de pesquisas geradas por linguistas em universidades brasileiras ou estrangeiras, mas também de textos publicados por missionários que atuaram entre os referidos povos na segunda metade do século Xx. A seleção das fontes se deu a fim de refletir a diversidade de aspectos gramaticais tratados. Metodologicamente, os textos foram coletados através de pesquisas na internet contando, inclusive, com o auxílio de informações contidas no livro Contemporary Carib-speaking Amerindians: A bibliography of social anthropological and linguistic resources, de Ernst Halbmayer (2013). Com o auxílio destas ferramentas, chegamos a textos relacionados às línguas Apalaí, Kaxuyana, Tiriyó e Wayana; importa ressaltar de antemão a presença ao longo do artigo de distintas formas gráficas relacionadas aos nomes das línguas, o que se deve à opção adotada de utilizar as grafias conforme utilizadas pelos autores dos textos. Para efeito de organização destes, optamos por apresentá-los conforme (i) sequência de ordem alfabética de autoria e, no caso de mais de um trabalho de mesmo autor, (ii) conforme sequência cronológica ascendente. Essa apresentação se dará em três partes distintas, sendo a primeira destinada ao conjunto de textos com escopo em descrição gramatical, a segunda destinada ao conjunto de textos com escopo em estudos histórico-comparativos e a terceira destinada a projetar distintas direções relacionadas aos estudos linguísticos dessa área.

O primeiro texto, Aspectos da fonologia Wayana, de Camargo (1996), é apresentado como resultado preliminar de análises do sistema fonológico da língua Wayana. Segundo a autora, há na língua os seguintes tipos silábicos: v, CV, CVV, CVC, CCV. Antes de tratar especificamente de vogais e de consoantes, Camargo destaca duas características do sistema fonológico: "(a) duas séries de três vogais, uma alta e outra média; (b) ausência de 


\section{GOMES \& FERREIRA - PANORAMA DOS ESTUDOS LINGUÍSTICOS...}

oposição de vozeamento das consoantes obstruintes". Para o caso das vogais, utilizandose de um conjunto de pares mínimos, a autora descreve um total de sete vogais orais. Na sequência, em seção intitulada "Regras de Realização", apresenta quatro processos vocálicos, a saber: nasalização, redução, harmonia e alongamento vocálico. Para o caso das consoantes, também se utilizando de um conjunto de pares mínimos, Camargo considera um total de nove segmentos, sendo cinco coronais, três labiais e um segmento velar. A autora trata ainda dos seguintes processos consonantais: vozeamento de oclusivas, lenição de oclusivas, palatalização das coronais /t/ e /s/, nasalização das oclusivas, glotalização da velar /k/, laringalização da fricativa /s/, velarização da fricativa /s/ e variação contextual das aproximantes $/ \mathrm{w} / \mathrm{e} / \mathrm{r} /$.

Em Classes verbais e semântica dos argumentos em um sistema sintático cindido: o exemplo do wayana (caribe), Camargo (2003a) apresenta (i) uma análise do sistema sintático Wayana em que operam dois padrões de alinhamento na codificação dos argumentos verbais: um ativo, outro absolutivo e (ii) realiza um estudo preliminar sobre valor do sufixo -ja em diferentes contextos actanciais e circunstanciais em Wayana (Camargo 2003a: 3). O texto está dividido em quatro seções. Na primeira, são apresentadas características gerais da língua. Na segunda, a autora aborda as classes verbais e indicialização. Na terceira seção, discute sobre os Índices actanciais, que estão classificados nos itens: (i) forma, segundo os dados apresentados pela autora, "os índices pessoais expressam relação entre $\mathrm{A}-\mathrm{P}^{4}$ sob uma única forma morfológica (conhecida sob o nome de forma sagital e portmanteau)" (cf. Camargo 2003a: 14) e (ii) sentido, no qual os índices pessoais possibilitam distintas observações sobre o "valor de cada uma das formas em relação ao semantismo do verbo" (cf. Camargo 2003a: 15). Na última seção, Cisão sintática operada pela indicialização, a autora esclarece que em Wayana a classificação do verbo corresponde à "oposição ativo/inativo em que o controle e o não controle da ação" (cf. Camargo 2003a: 17) são considerados traços semânticos fundamentais. Ainda nesta seção, a autora afirma que a análise apresentada não oferece elementos que possam afirmar que a língua Wayana conheça uma sintaxe ergativa, a não ser pela cisão morfossintática.

Relações sintáticas e semânticas na predicação nominal do Wayana: a oração com cópula, de Camargo (2003b), visa a retratar "uma ilustração da irregularidade da forma da cópula (-a-/eha-) e seus empregos", bem como a realizar uma "análise descritiva da construção «Subst/Adj/Loc(- $\left.\S^{5}\right)$ índice.pessoal-cópula», ou seja «Y(-§) X-cópula»”, considerando seus diferentes campos semânticos. A primeira seção trata da predicação nominal na língua Wayana. Segundo a autora, a relação predicativa nominal entre dois elementos pode ser realizada com ou sem a presença da cópula (-a-/-eha-). No que se refere à relação predicativa nominal marcada pela presença da cópula, discussão realizada na seção dois, Camargo considera que esta tem a função de construtor de predicado. Nas seções três e quatro, a autora aborda o valor da relação predicativa realizada pelas estruturas «Y X-cópula» e «Y-§ X-cópula». Na quinta seção, A admonestatividade expressa pela $3^{a}$ pessoa: nai, a autora apresenta o caso da $3^{\mathrm{a}}$ pessoa "representado pelo prefixo $n$-, que se prende à cópula $-a->n-a-i$ (3ser/estar-sit) e -eha $>n$-eha (3- ser/estar.passado), porém

${ }^{4}$ Em nota de rodapé, Camargo (2003a: 2) atribui à abreviação A valor Agente e à abreviação $\mathrm{P}$ valor Paciente.

${ }^{5}$ Símbolo utilizado pela autora para identificar diferentes morfemas que se unem a Y. 
a construção em concomitância com T, n-a-i (>3sg-ser/estar-sit) 'ele é/está', aparece nas orações «Y X-ser/estar»" (cf. Camargo 2003b: 153-154), dessa forma apresentando características semânticas particulares, tais quais como a de um admonestativo. Na sexta seção, a autora discorre sobre mudança na percepção aspecto-temporal, que consiste em variações aspecto-temporais conforme a referência enunciativa concomitante ou não com T. Ao final, Camargo (2003b: 157) afirma que "no falar Wayana contemporâneo, a cópula apresenta uma supleção que codifica aspecto-tempo".

No texto Operadores aspectuais de estado marcando o nome em wayana (caribe) Camargo (2008) analisa quatro operadores aspectuais de estado que se prendem ao nome, seja animado, seja inanimado: -me, -ø, -tpë, -npë. A autora discorre sobre maneiras como a língua Wayana constitui o seu mundo referencial. Com os quatro operadores aspectuais em questão, Camargo busca verificar 'o 'estado' que pode expressar um estado evolutivo (-me) ou um estado de atividade (-ø), com um processo subjacente, ou um 'estado' que, ao se referir ao estado anterior, indica um processo acabado (-tpë/tpi) ou (-npë/npi)" (cf. Camargo 2008: 86). Ao final do artigo, a autora considera que sua análise aponta para diferentes valores de estado, inclusive que "semantismo lexical também contribui para a significação da relação predicativa" (cf. Camargo 2008: 102).

Aspectos da gramática Wayana são tratados no texto Trois chants de guerre wayana (Camargo; Riviere 2001, 2002) com o fim de particularizar a língua cantada da língua falada. Utilizando-se dos cantos pülëu kalau "canção da flecha", asimhak ïtë-top "ir rápido" e epu-lë-më-top "para ser picado novamente", Camargo e Riviere destacam a existência nestes de palavras não atestadas na língua falada. Da mesma forma, os autores particularizam as duas formas de linguagem utilizando-se de características fonéticas, por exemplo, relacionadas à realização da fricativa $/ \mathrm{s} /$ naquela e $/ \mathrm{h} /$ nesta, à alofonia envolvendo [o] presente na língua cantada e [ë] presente na língua falada. Na sequência do texto, ainda com o fim de particularizar as duas formas de linguagem, Camargo e Riviere discorrem sobre processos morfofonológicos envolvendo os morfemas imperativo $-k o,-k \ddot{e}$, plural -tomo, hortativo -ta, aspecto -tpë e -me, terminativo -npë, demonstrativo negativo -p̈̈n. Nas considerações finais do artigo, um aspecto destacado pelos autores e que gostaríamos de mencionar se refere à relação das gerações atuais com os cantos antigos dos Wayana, caracterizada, segundo Camargo e Riviere (2001, 2002), como uma relação de distanciamento das novas gerações Wayana com sua própria história.

Em texto de (2019) intitulado Estratégias da posse em wayana e seu mosaico morfo(fono)lógico, Camargo e Wajana apresentam uma descrição de estruturas de posse da língua. Na primeira seção, os autores informam sobre procedimentos metodológicos relacionados à coleta de dados a partir de elicitações, de narrativas, de cantos rituais e experiência de campo, bem como remontam a trabalhos já realizados sobre o tema (Camargo 1999, 2019; Jackson 1972; Tavares 2005). Na segunda seção, os autores tratam da (i) A estrutura geral do enunciado fundamental wayana; (ii) Predicação nominal; (iii) A ordem dos elementos no sintagma nominal; (iv) de Alguns fenômenos morfofonológicos. Em Tipos de construções de posse, os autores afirmam que em construções de posse, "a relação semântica entre os elementos é diversa e distinta morfologicamente; ela apresenta nuances semânticas, cada uma devidamente distinguida pela morfologia" (cf. Camargo; Wajana 2019: 14). A análise dos autores resulta em quatro estruturas de posse: posse canônica, reflexiva, aspectualizada e posse restritiva. Na quarta seção, Camargo e 


\section{GOMES \& FERREIRA - PANORAMA DOS ESTUDOS LINGUÍSTICOS...}

Wajana discutem posse expressando quantificação, bem como (i) posse expressando plural coletivo; (ii) posse expressando plural paucal; (iii) posse com pluralia tantum.

No texto The historical tense in Apalai Narrative, Edward Koehn (1976) trata da marca de tempo histórico - ko presente, segundo o autor, apenas em narrativas. Após análise da ocorrência de -ko em posição inicial e final de narrativas, o autor considera que o uso desta marca é mais frequente em algumas narrativas, o que sugere se tratar de escolhas feitas pelo narrador, que tem a sua disposição certas opções. Para além da posição de $-k o$, Koehn discute a relação desta marca com ideofones e com o destaque de participantes da narrativa. A relação com ideofones conduz o autor a duas perguntas, quais sejam: é o marcador -ko periférico ao ideofone servindo para identificar a ação por ele sinalizada? É o ideofone que é periférico, funcionando apenas como um destaque extra para a ação descrita pela forma do verbo $-k o$ ? A resposta a estas perguntas é construída pelo autor com base nos conceitos de tema e rema (Halliday 1967), cujos efeitos recaem sobre o destaque dos participantes da narrativa.

A seguir, dois textos de Edward Koehn publicados no ano de 2009. The Apalai phrase: preliminary analysis de Koehn (2009a), apresenta uma breve análise sobre a estrutura verbal da língua Apalaí. $\mathrm{O}$ autor discorre sobre as estruturas das frases Apalaí e sua função dentro de uma oração. Segundo o autor, há vários tipos de frases que se caracterizam conforme sua estrutura interna e sua distribuição na oração. O primeiro tipo de frase que Koehn apresenta é a frase nominal, dividida em oito subtipos: Frase de posse; Frase modificadora; Frase de acompanhamento; Frase descritiva; Frase de atribuição; Frase instrumental; Frase ocupacional; Frase nominal simples. O segundo tipo de frase é aquele constituído pela presença de um verbo ou de um complexo verbal; três subtipos são apresentados: Frase independente; Frase auxiliar e Frase ideófona. Um terceiro tipo de frase é a frase do eixo do relator (Relator-axis phrase). O quarto tipo apresentado pelo autor é a frase de partícula. O quinto tipo é aquele composto por partículas posposicionais.

O segundo texto publicado por Edward Koehn no ano de 2009, Bound person markers of the Apalai verb phrase: preliminary analysis, trata dos prefixos pessoais relacionados à marcação de pessoa sujeito, de objeto e de possuidor. A análise da marcação de sujeito e de objeto é feita com base em paradigma composto por cinco pessoas, a saber: 1a, 2a, 3a, 1a inclusiva e 1a pessoa exclusiva. Tais paradigmas são sintetizados pelo autor em um quadro cujo objetivo é demonstrar a correlação que se estabelece entre ambas em uma estrutura com verbo transitivo flexionado. A marcação de possuidor, assentada no mesmo paradigma de pessoas, é atrelada à estrutura na qual, junto à raiz verbal, co-ocorrem prefixo de possuidor e sufixo de posse /-ry/. Essa estrutura, segundo Koehn (2009b), não funciona sintaticamente como verbo, mas como nome ou descritivo. $\mathrm{Na}$ sequência do artigo, o autor trata dos afixos seguintes: finalidade, reflexivos, coletivizadores, marcas de posse, objetos indiretos.

Koehn e Koehn (1971), em Fonologia da língua Apalaí, tratam do sistema fonológico da língua Apalai, particularmente dos fonemas consonantais e vocálicos, dos padrões silábicos e do acento. Ao se referir aos fonemas consonantais e vocálicos, os autores apresentam um total de doze fonemas consonantais, a saber: /p/, /m/, /w/, /t/, /n/, /z/, /s/, /r/, /x/, /i/, /k/, /\%, seis fonemas vocálicos orais e seis fonemas vocálicos nasais, conforme segue (com diacríticos usados pelo autor): /i/, /y/, /u/, /e/, /a/, /o/, /in/, /yn/, /un/, /en/, / $\mathrm{a}^{\mathrm{n}} /, / \mathrm{o}^{\mathrm{n}} /$. Em seção intitulada Distribuição, os autores explicam que os padrões silábicos 
da língua Apalaí constituem-se em "uma vogal nuclear V, com margem consonântica inicial e final, $\mathrm{C}$, ou sem margem consonântica inicial e com a margem final ou com margem consonântica inicial sem a final" (cf. Koehn; Koehn 1971: 4). Os autores tratam de quatro diferentes tipos de padrões silábicos: V, VC, CV e CVC. Dentre esses padrões, CV é o mais recorrente. A última seção é destinada ao tratamento do "acento intensivo". De acordo com os autores, o acento intensivo, também chamado de secundário, sob ponto de vista fonológico, manifesta-se quando a penúltima sílaba é acentuada, ocorrendo em três momentos: (i) palavras com apenas uma sílaba; (ii) sílabas travadas ou sílabas nasais próximas a pelo menos uma sílaba não acentuada; (iii) sílaba inicial das palavras de quatro ou mais sílabas quando a segunda sílaba não é acentuada.

Apalai, também de Koehn e Koehn (1986), apresenta um panorama de aspectos da fonologia, da morfologia, da sintaxe e da estruturação do texto Apalaí. Na seção inicial, os autores tratam de aspectos da sintaxe relacionados à sentença simples e à sentença complexa, bem como aos sintagmas nominal e verbal. No caso da sentença simples, os autores tratam dos tipos básicos: intransitivo, transitivo, expressivo, copular e equativo; tratam também dos constituintes opcionais da sentença: objeto indireto e objetos oblíquos. Koehn e Koehn abordam temas relacionados à parataxe, à elipse de constituintes nãoverbais, aos prefixos verbais reflexivos e recíprocos, a estruturas sintáticas passivas, causativas, comparativas, à coordenação. Em seção intitulada Características pragmáticas e discursivas, os autores dissertam sobre sentenças interrogativas, imperativas e negativas. No que se refere às sentenças complexas, Koehn e Koehn apresentam treze tipos de sentenças subordinadas. Após discorrer sobre cada um dos tipos, os autores tratam da estrutura de sintagmas nominais, do sistema pronominal da língua, de adposições, da estrutura de sintagmas verbais, de partículas. Finalmente, os autores dedicam-se à aspectos da fonologia Apalaí, incluindo a estrutura silábica, segmentos consonantais e vocálicos, suprassegmentos, morfofonologia e ideofones. ${ }^{6}$

Em texto intitulado Apalai verb structure: Preliminary analysis, Sally Koehn (2009) faz uma análise da estrutura verbal da língua Apalaí. A autora trata do que denomina camadas significativas do verbo: a camada do núcleo, a camada raiz e a camada completa da palavra. Segundo Koehn, a camada do núcleo é caracterizada por uma única raiz ou uma combinação de raízes. A camada raiz é o núcleo do verbo com ou sem afixos derivativos. A camada completa da palavra dos verbos em Apalaí consiste em raízes verbais e afixos flexionados. Além disso, em seção intitulada Alomorfes, Koehn apresenta cinco tipos de alomorfias produtivos nos verbos Apalaí causados por: alomorfes de prefixos derivados e sufixos flexionais; alomorfes de prefixos flexionais; alomorfes de raiz; alomorfes do verbo declarativo não transitivo; alomorfes do verbo declarativo estativo.

${ }^{6}$ Koehn e Koehn (1995) são autores também do Vocabulário Básico, Apalaí-Português: Dicionário da Língua Apalaí. Para o caso Wajana, o Dicionário bilíngue Wayana-Français de Camargo; Tapinkili; Akajuli; Atajumale; Hernandez (2009). 


\section{GOMES \& FERREIRA - PANORAMA DOS ESTUDOS LINGUÍSTICOS...}

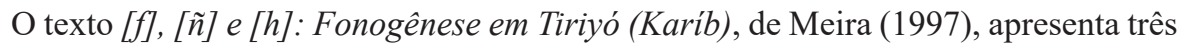
fones da língua Tiriyó, [f], [ñ] e [h] que, segundo o autor, são problemáticos. ${ }^{7}$ Tais fones revelam “[...] interações com o sistema de acento rítmico do Tiriyó, que sugerem uma análise baseada em grupos consonantais subjacentes" (cf. Meira 1997: 167). De acordo com o autor, esses fones estão a ponto de se tornarem fonemas independentes, o que conduz Meira à proposta de realização de uma reanálise desses fones como segmentos simples. $\mathrm{O}$ autor inicia a primeira seção do artigo explicando o sistema de acento rítmico Tiriyó, "caracterizado pela ocorrência de acento secundário em todas as sílabas pares de uma palavra fonológica, contando-se da esquerda para a direita, com exceção da sílaba final, que nunca recebe acento" (cf. Meira 1997: 168). Em seguida, Meira discorre sobre cada um dos fones mencionados. Ao final do texto, o autor ressalta que "embora estes três fones possam ocorrer e até contrastar com outros fonemas consonantais em início de sílaba, o efeito perturbador que eles exercem sobre o padrão acentual rítmico é ainda capaz de isolá-los como casos à parte" (cf. Meira 1997: 176).

Meira (1998) apresenta o texto Rhythmic stress in tiriyó (cariban) como “[...] uma tentativa de descrição preliminar do padrão acentual rítmico encontrado em Tiriyó" (Meira 1998: 353). Já na primeira seção do texto, utilizando-se de uma tabela com palavras agrupadas por número de sílabas, Meira (1998: 353) faz a seguinte generalização acerca do padrão rítmico Tiriyó: "contando do início da palavra, toda segunda sílaba tem uma vogal longa com pitch alto, com exceção da última sílaba, que nunca é longa ou alta”. Utilizando-se dos tipos (C)vC, (C)Vv, (C)Vvc e (C)v, Meira trata do peso silábico e da interação deste com o padrão acentual rítmico. A análise apresentada acerca dos referidos tipos silábicos é sintetizada pelo autor nos seguintes termos: “[...] a atribuição de acento secundário trata as sílabas (C) VC, (C)VVC, (C)VV e (C)v de maneira diferente das sílabas (C) v" (cf. Meira 1998: 361). De acordo com o autor, as primeiras são inerentemente sílabas pesadas, enquanto (c)v são sílabas inerentemente leves. Na sequência do texto, Meira (1998: 362) discute peso silábico de uma perspectiva histórica, ocasião em que considera que sílabas inerentemente leves causadas por processo de redução silábica, atestado sincronicamente, sugerem processo diacrônico similar; tal processo pode ser estendido a casos de pesos subjacentes de outras línguas Karíb. Em seção intitulada Special Cases, Meira (1998: 363) discorre sobre o padrão acentual rítmico de palavras monossilábicas e de palavras bissilábicas. Após a apresentação e a análise dos dados, o autor as discute utilizando-se de teorias advindas da Fonologia Métrica (Liberman 1975; Liberman; Prince 1977). Nesse contexto, Meira, em referência ao trabalho de Hayes relacionado à língua Hixkaryana (Hayes 1995), considera que “[...] a única diferença relevante entre Tiriyó e Hixkaryana é o conjunto de sílabas leves, maior em Tiriyó.” (cf. Meira 1998: 368). Na última seção do texto, Meira discute acento rítmico nas línguas Kaxuyana, Hixkaryana, Macushi.

A tese de Meira (1999), A grammar of Tiriyó, um dos trabalhos mais robustos acerca de uma língua do Complexo do Tumucumaque, traça um panorama gramatical da língua

${ }^{7}$ Discussões sobre o fone [h] são encontradas em Parker (2001). Em texto intitulado On the phonemic status of [h] in Tiriyó, Parker (2001), ao apontar para o tratamento de [h] como fonema contrastivo restrito a posição final de sílaba (Jones 1972; Meira 1998), propõe análise em que o referido fone é tratado como alofone neutralizado das obstruintes $/ \mathrm{p} \mathrm{t} \mathrm{k} \mathrm{s/.}$ 
Tiriyó. Composta por onze capítulos, a Tese trata nas informações iniciais de características genéticas da língua, de características geográficas e demográficas da população. Após o panorama em questão, Meira aborda a Fonologia Tiriyó. Na sequência, trata da unidade morfológica, de fenômenos categóricos cruzados e de classes lexicais (nomes e pronomes, verbos, advérbios, posposições, interrogativos e partículas). O Capítulo quatro trata da classe nome, onde são discutidos aspectos dos pronomes, da derivação, da flexão (de posse, número e vocativos). No Capítulo seguinte, o autor trata da classe verbo, indicando ser esta a mais fácil de classificar. Em vista disso, o autor apresenta quatro aspectos caracterizadores do verbo, a alomorfia da raiz, as subclasses morfossintáticas, a derivação e a flexão. Em seguida, o autor trata dos advérbios, classificados em advérbios morfofonêmicos e advérbios derivados. Posposições é o tema do Capítulo sete. Em seguida, Meira (1999) trata dos interrogativos, caracterizados como um grupo de elementos da classe nominal e adverbial que compartilham algumas propriedades. O Capítulo nove trata das partículas da língua, classificadas em dois conjuntos: partículas gramaticais e partículas lexicais. No Capítulo dez, Meira aborda a sintaxe da língua Tiriyó em cinco subseções: introdução, frases, orações e sentenças, sentenças complexas e observações preliminares sobre rheme e ordens das palavras. No último Capítulo, o autor trata de questões de léxico e de semântica lexical inerentes à língua Tiriyó.

O texto Notas fonológicas da língua, Tiriyó de Migliazza, (1965), consiste na análise de aspectos relacionados a fonemas, a sílabas, a vocábulos fonológicos, a grupo de entonação e a grupo de pausa da língua Tiriyó. A primeira seção aborda os fonemas. De acordo com Migliazza, a língua Tiriyó possui dezessete fonemas segmentais, sendo dez consoantes e sete vogais, além de um fonema suprassegmental. As dez consoantes são: $/ \mathrm{p} /$, $/ \mathrm{t} /, / \mathrm{k} /, / \mathrm{x} /, / \mathrm{m} /, / \mathrm{n} /, / \mathrm{n} /, / \mathrm{r} /, / \mathrm{w} /, / \mathrm{y} /$, enquanto que as sete vogais são: /i/, /e/, /i//,/ə/, /a/, /u/, /o/. O fonema suprassegmental /'/ é tratado na seção Vocábulo fonológico, onde o autor aborda os acentos primário e secundário. Na seção dedicada à estrutura da sílaba reconhece quatro padrões silábicos: v, CV, vc, CVC. O vocábulo fonológico Tiriyó é, segundo o autor, "um componente do grupo de entonação. Distingue-se pelo acento vocabular e pela juntura externa aberta que marca as fronteiras vocabulares especialmente na fala tipo "lento"' (cf. Migliazza 1965: 8). Quanto ao grupo de entonação, caracterizado como unidade rítmica da fala Tiriyó, compõe-se de acento frasal, de entonação e de juntura. De acordo com o autor, o grupo de entonação "é composto de um a cinco vocábulos fonológicos com um único acento forte frasal, que ocorre na última e penúltima do último vocábulo" (cf. Migliazza 1965: 9). Conforme a entonação, Migliazza identifica dois grupos: a entonação ascendente e a entonação sustenida ${ }^{8}$ com transição final descendente ou pela entonação descendente. O último aspecto fonológico que o autor aborda é o grupo de pausa, tratado como um componente do discurso em Tiriyó.

A grammar of Wayana, Tese de doutorado de Tavares (2005), após apresentar informações sobre a população Wayana, perfaz um caminho que inicia na fonologia e chega à sintaxe da língua. Tavares (2005) apresenta informações que se relacionam: (i) aos segmentos consonantais e vocálicos; (ii) à Fonotática; (iii) à Morfofonologia; (iv) à Prosódia; (v) a Casos marginais. Na seção dedicada à morfologia, a autora trata de

\footnotetext{
${ }^{8}$ Segundo Migliazza (1965: 9), entonação sustenida significa sustentar o tom 2, ou mais baixo que o 2, até a última sílaba do grupo de entonação e terminar com uma pequena transição descendente.
} 


\section{GOMES \& FERREIRA - PANORAMA DOS ESTUDOS LINGUÍSTICOS...}

partículas e de sufixos, de prefixos de terceira pessoa e de partes do discurso. No caso das classes de palavras, ao tratar dos nomes, Tavares (2005) discute flexão, derivação, pronomes e casos especiais. Para a classe dos verbos, a autora discute o que considera seis pontos importantes em relação ao verbo Wayana: a alomorfia verbal, classes verbais morfossintáticas, flexão, morfemas derivacionais, incorporação do substantivo e a reduplicação. Após o tratamento das classes nome e verbo, a autora trata de posposições e de advérbios. O último capítulo da Tese, destinado ao tratamento da sintaxe da língua, discute grupos de constituintes, relações gramaticais e tipos de oração.

Wallace (1970), em texto intitulado Notas fonológicas da língua Kaxuyana, apresenta aspectos relacionados a fonemas, a sílabas, a vocábulos fonológicos e a grupos de entonação. No que se refere a fonemas, a autora apresenta onze consoantes: /p/, /t/, /k/, /m/, /n/, /s/, /h/, /r/, /w/, /y/, /? ${ }^{9} /$ e seis vogais: /i/, /i/, /u/, /e/, /o/, /a/. Quanto à sílaba, a autora apresenta os padrões: V, VC, CV, CVC, CCV, sendo CV o mais recorrente. Ao analisar a palavra fonológica, a autora considera que nem sempre a palavra fonológica coincide com a palavra morfológica. Ao tratar dos grupos de entonação, assim como em outras línguas caribe (Tiriyó, por exemplo), segundo Wallace, "o grupo de entonação constitui a sua unidade rítmica de fala e é caracterizado pelo acento frasal, juntura e entonação" (cf. Wallace 1970: 18).

Harmonia vocálica nos afixos de posse na língua Kaxuyâna, de Wallace (1976), trata da mudança ocorrida na harmonia vocálica em Kaxuyâna. No caso da marcação de posse afixal dos nomes em Kaxuyâna, segundo a autora, há dois casos específicos que desencadeiam harmonia vocálica, quais sejam: prefixo de $1^{\mathrm{a}}$ pessoa plural e sufixos possessivos. Ao final do texto, Wallace (1976) destaca que em Kaxuyâna há três tipos de harmonia: a) harmonia essencialmente vocálica que ocorre com o prefixo $k u$ - e com os sufixos ${ }_{1} ;{ }^{10}$ b) harmonia em alguns casos apenas vocálica e, em outros, consonantal e vocálico, como ocorre com o prefixo $k i ̈$; c) harmonia determinada pela consoante e pela vogal, como ocorre como os prefixos $k o-$, $k a$ - e $k i$-.

Em Notas verbais da língua Tiriyó (Karíb), Wallace (1980) apresenta dados da língua Tiriyó visando a aspectos da morfologia verbal dessa língua. Para contextualizar sua análise, a autora discute aspectos da Fonologia Tiriyó (cf. Migliazza 1965), abordando, resumidamente, as vogais, as consoantes e as sílabas. Na sequência, a autora trata especificamente do escopo do texto, o verbo. Essa seção está dividida nas seguintes subseções: Verbos Regulares, Prefixos pessoais, Verbos transitivos e intransitivos, Tempos verbais, Modos verbais e Verbos estativos. Segundo Wallace (1980), os verbos em Tiriyó consistem em uma classe diferente das demais classes de palavras, pois são flexionados por meio de afixos de pessoa, objeto, negação, tempo, modo e outros. Os temas verbais são divididos em duas classes maiores, classificados pela autora como regular e irregular. ${ }^{11}$ Para além da regularidade e da irregularidade dos verbos, a autora descreve outros aspectos

${ }^{9}$ Denominada pela autora como oclusiva faucal, é considerada como possível resultante de eliminação de uma vogal em sílaba CV no qual C seja fricativa faucal aspirada $/ \mathrm{h} /$.

${ }^{10}$ Wallace (1980) afirma que os sufixos de posse caracterizam as subclasses a que pertencem os temas nominais quando possuídos (sufixo 1) ou indicam posse de mais de duas pessoas (sufixo 2).

${ }^{11}$ Wallace (1976) ao final do texto explica que os verbos irregulares não foram explorados com detalhes por falta de material adequado. 
como os afixos pessoais, a transitividade e a intransitividade da ação verbal, o tempo, o modo e os verbos estativos.

Estudos como os discriminados até aqui demonstram escopo em descrições de aspectos da gramática das línguas Apalaí, Kaxuyana, Tiriyó e Wayana. Estudos sobre essas línguas têm servido também para a realização de estudos histórico-comparativos, o que inclui informações provenientes de línguas Karíb faladas em regiões para além do Complexo do Tumucumaque. Esse é o caso do texto de Meira (1998) discutido anteriormente, que trata do acento rítmico em Tiriyó comparado ao acento rítmico de outras línguas Karíb. Para além desse, mencionamos a seguir outros textos histórico-comparativos que contêm dados de línguas Karíb.

Em Sistemas contrastivos de marcadores de pessoa em duas línguas Carib: Apalaí e Hixkaryána, Gudschinsky (1973) compara os sistemas de prefixos pessoais dos verbos transitivos e intransitivos presentes nas duas línguas em questão. A análise da autora aponta para as seguintes características inerentes aos sistemas prefixais das duas línguas: a) qualquer primeira ou segunda pessoa do sujeito é sempre expressa com exclusão de qualquer indicação do objeto; b) uma primeira ou segunda pessoa do objeto é expressa com exclusão de qualquer indicação de uma terceira pessoa do sujeito; c) a terceira pessoa é expressa somente quando ambos, sujeito e objeto (se houver), referem-se a terceira pessoa. Como resultado da análise, Gudschinsky afirma que em Apalaí há duas categorias não-marcadas como prefixos verbais, primeira e terceira pessoa do sujeito, e uma categoria parcialmente marcada, terceira pessoa do objeto. No que se refere à língua Hixkaryána, ${ }^{12}$ segundo a autora, há oito categorias marcadas, sendo que cinco dessas categorias têm formas contrastivas que indicam transitivo, intransitivo ou estativo.

A classificação interna da família Karíb é um problema ainda não resolvido, uma vez que muitas línguas da família ainda são pouco conhecidas. Essa constatação de Meira (2000: 10; Gildea 1998: 3-14) inicia o texto A reconstruction of proto-taranoan: phonology and morphology (Meira 2000), cuja pretensão é “[...] ser uma pequena contribuição para o estabelecimento das bases sobre as quais uma melhor classificação da família Karíb pode se dar" (cf. Meira 2000: 10). Proto-Taranoano se refere ao conjunto das línguas Tiriyó, Akuriyó e Karihona. ${ }^{13}$ Para a reconstrução de aspectos da Fonologia e da Morfologia dessas três línguas, o autor parte de revisão fonológica de cada uma das mesmas línguas para, em seguida, apresentar correspondências e proto-segmentos a elas relacionadas. Em capítulo intitulado Sketch of the historical phonology of taranoan languages, Meira (2000: 51), dentre outros, reconstrói para o Proto-Taranoano sete vogais, onze consoantes, aproximadamente treze ditongos e onze consoantes complexas. No mesmo capítulo, o autor trata da origem das vogais longas em Tiriyó. Na reconstrução da morfologia Proto-Taranoano, Meira trata de diferentes tipos de pronomes, de nomes, de posse, de nominalização, de posposições, de verbos, de formas imperativas, negativas, de verbalização, dentre outros. Meira (2000) apresenta ainda capítulos contendo Esboço

\footnotetext{
${ }^{12}$ As populações Hixkaryana (Karíb) vivem atualmente em porções de terras localizadas entre os estados do Amazonas e do Pará. Segundo o Instituto Socioambiental, fontes históricas apontam para a presença deste povo nessas terras já no século XVIII.

https://pib.socioambiental.org/pt/Povo:Hixkaryana\#Localiza.C3.A7.C3.A3o_e_hist.C3.B3rico_do_contato.

${ }^{13} \mathrm{O}$ povo Karihona vive na Colômbia, próximo à fronteira brasileira.
} 


\section{GOMES \& FERREIRA - PANORAMA DOS ESTUDOS LINGUÍSTICOS...}

da morfologia histórica das línguas Taranoanas, algumas observações sobre a história Taranoana e o Primeiro dicionário etimológico Taranoano, composto por 433 entradas. Junto ao dicionário, Meira apresenta Lista alfabética de formas reconstruídas e lista de Formas reconstruídas organizadas por classes de palavras e por campos semânticos. O autor apresenta dois apêndices, sendo o primeiro um texto de cada uma das línguas que constituem o Proto-Taranoano e o segundo, um conjunto de informações classificadas como menos acessíveis acerca destas línguas.

Mudança sintática em andamento: o caso dos "classificadores genitivos" em línguas caribes é outro texto de natureza histórico-comparativa publicado por Meira. No texto em questão, Meira (2016), trata das construções com classificadores genitivos nas línguas Apalaí (Koehn; Koehn 1986, 1994) e Panare (Mattei-Muller 1974; Payne; Payne 1989, 2013), com o fim de compará-las ao que ocorre em Tiriyó. Como resultado das análises do tema em questão, Meira (2016) conclui que as línguas Apalaí e Tiriyó são semelhantes, pois têm construções com termos genéricos em que termos específicos podem ser opostos, porém sem a coesão sintática mais forte encontrada em sintagmas possessivos. Por outro lado, a língua Panare ${ }^{14}$ distingue-se daquelas duas línguas por apresentar: (i) pausas entre termos genérico e específico, significativamente mais raras nesta língua e praticamente obrigatória em Apalaí e Tiriyó; (ii) o termo genérico e o específico podem ser o mesmo, ou seja, ocorre repetição dos termos. Sobre esses resultados, Meira (2016) afirma que "não há dados disponíveis para o Panare e o Apalaí (de fato, para nenhuma língua caribe, exceto o Tiriyó) sobre o nível exato de coesão sintática entre os termos genérico e específico" (cf. Meira 2016: 98).

Em Comparação de afixos de posse em línguas Karíb, Wallace (1983) analisa o sistema de afixação de posse das línguas Apalaí, Tiriyó, Kaxuyana e Waiwai. A autora considera "os processos fonológicos e morfológicos que se apresentam nos temas nominais dessas línguas ao se tornarem possuídos" (cf. Wallace 1983: 1). Na sequência, Wallace trata de perda vocálica, de mudança de consoante, de palatalização, de harmonia vocálica. De acordo com a autora, dentre os diversos processos morfofonêmicos que ocorrem nos sistemas de posse nominal do Apalaí, Waiwai, Kaxuyana e Tiriyó, destacam-se dois deles, (i) a harmonia vocálica (consonantal), com ocorrência nas línguas Kaxuyana, Apalaí e Waiwai; (ii) a mudança consonantal $\mathrm{p} \rightarrow \mathrm{h}$, nas línguas Waiwai, Kaxuyana e Tiriyó. Essa mudança consonantal, segundo a autora, pode ser uma das chaves para a elucidação da história das línguas Karíb. Vale ressaltar acerca dessa mudança os textos já mencionados de Meira (1997) e Parker (2001), que também apresentaram análises relacionadas a [h] em Tiriyó.

Outros estudos histórico-comparativos que contêm dados das línguas Karíb do Complexo do Tumucumaque são encontrados em Derbyshire (1999); Gildea (1995, 1998,

${ }^{14}$ Panare é uma língua Karíb falada por população de mesmo nome que vive na Venezuela. Nos termos de Meira (2006), trata-se de um grupo relativamente saudável, onde todos falam a sua língua. http://www.funai.gov. br/arquivos/arquivos_old/conteudo/cogedi/pdf/revista_estudos_pesquisas_v3_n1_2/06A_famil ia_linguistica_ Caribe_Karib_Sergio_Meira.pdf.

A língua Waiwai mencionada no texto de Wallace (1983), segundo o Instituto Socioambiental, é falada por populações que “... encontram-se dispersos em extensas partes da região das Guianas”. https://pib. socioambiental.org/pt/Povo:Waiwai. 
2012); Meira (2006). O quadro a seguir resume o panorama constituído pelos textos até aqui discutidos:

Quadro 1: Resumo de estudos linguísticos descritivos e histórico-comparativos das línguas Karíb do Tumucumaque

\begin{tabular}{|c|c|c|}
\hline LÍNGUA & $\begin{array}{l}\text { DESCRIÇÃO DE ASPECTOS DA } \\
\text { GRAMÁTICA }\end{array}$ & HistóRICO COMPARATIVO \\
\hline Apalai & $\begin{array}{l}\text { Fonologia (Koehn; Koehn 1971) } \\
\text { Morfologia (Koehn, E. 1976; } \\
\text { Koehn, E. 2009) } \\
\begin{array}{l}\text { Sintaxe (Koehn; Koehn 1976; } \\
\text { Koehn, S. 2009) }\end{array}\end{array}$ & $\begin{array}{l}\text { Morfossintaxe de marcação de pessoa } \\
\text { Apalaí e Hixkaryána (Gudschinsky } \\
\text { 1973) } \\
\text { Morfossintaxe de marcação de Posse } \\
\text { Apalaí, Tiriyó Kaxuyana e Waiwai } \\
\text { (Wallace 1983) } \\
\text { Morfossintaxe de classificadores ge- } \\
\text { nitivos Apalaí, Panare e Tyriyó (Meira } \\
\text { 2016) }\end{array}$ \\
\hline Kaxuyana & $\begin{array}{l}\text { Fonologia (Wallace 1970, 1976) } \\
\text { Morfologia (Wallace 1980) }\end{array}$ & $\begin{array}{l}\text { Morfossintaxe de marcação de posse } \\
\text { Apalaí, Tiriyó Kaxuyana e Waiwai } \\
\text { (Wallace 1983) }\end{array}$ \\
\hline Tiriyó & $\begin{array}{l}\text { Fonologia (Meira 1997, 1998, 1999; } \\
\text { Migliazza 1965) } \\
\text { Morfologia (Meira 1999; Wallace } \\
\text { 1980) } \\
\text { Sintaxe (Meira 1999) } \\
\text { Semântica Lexical (Meira 1999) }\end{array}$ & $\begin{array}{l}\text { Morfossintaxe de marcação de posse } \\
\text { Apalaí, Tiriyó Kaxuyana e Waiwai } \\
\text { (Wallace 1983) } \\
\text { Morfossintaxe de classificadores } \\
\text { genitivos Apalaí, Panare e Tiriyó } \\
\text { (Meira 2016) }\end{array}$ \\
\hline Wayana & 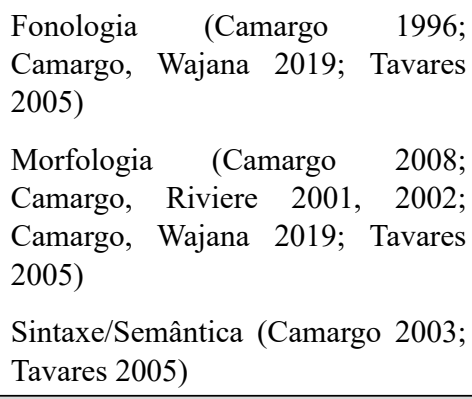 & \\
\hline Proto-Taranoano & & $\begin{array}{l}\text { A reconstruction of proto-taranoan: } \\
\text { phonology and morphology (Meira } \\
\text { 2000) }\end{array}$ \\
\hline
\end{tabular}

O presente quadro demonstra recorrência de estudos linguísticos relacionados a quatro línguas Karíb. A quantidade de informações que se tem disponível sobre as mesmas, contudo, é assimétrica no sentido de que Tiriyó e Wayana possuem diversidade de informações sobre suas gramáticas, enquanto que Apalai e Kaxuyana possuem quantidade 


\section{GOMES \& FERREIRA - PANORAMA DOS ESTUDOS LINGUÍSTICOS...}

reduzida de informações sobre suas gramáticas, além de produzidas na segunda metade do século XX, havendo descontinuidade de estudos sobre tais línguas nas décadas seguintes.

Sobre a língua Apalaí, os textos publicados, embora tratem de fonologia, de morfologia e de sintaxe, assim o fazem de maneira introdutória, sem grandes detalhamentos. A ausência de estudos linguísticos recentes e abrangentes sobre essa língua é um caso que merece ser observado com atenção, já que se trata de uma língua que goza de bastante prestígio social em diferentes contextos de uso. Para o caso Kaxuyana, temos informações sobre aspectos da fonologia, ressentindo-nos da ausência de informações sobre a morfologia e a sintaxe da língua. Mesmo as informações sobre aspectos da fonologia, assim como no caso da língua Apalaí, são introdutórias.

O quadro 1 evidencia a necessidade de estudos abrangentes voltados às línguas Apalai e Kaxuyana, assim como evidencia ausência de estudos com escopo na descrição gramatical ou de natureza histórico-comparativa acerca da língua Xikiyana, e a escassez de estudos sobre a língua Akuriyó. Conforme mencionamos no início do texto considerando notícias por nós recebidas, atualmente a língua Xikiyana caracteriza-se pelo número reduzido de falantes que vivem entre Tiriyó em distintas aldeias do Complexo do Tumucumaque. No caso da língua Akuriyó, a possibilidade de lembrantes.

O panorama dos estudos linguísticos no Complexo do Tumucumaque a partir do quadro 1 pode ser resumido conforme segue, em que reiteramos a necessidade urgente de estudos sobre as línguas Apalaí, Kaxuyana, Xikiyana e Akuriyó. Tais estudos se somariam aos estudos disponíveis sobre as línguas Tiriyó e Wayana:

- Ocorrência de estudos sobre as línguas Apalaí, Kaxuyana, Tiriyó e Wayana.

- Do conjunto de quatro línguas, as duas primeiras possuem informações publicadas entre os anos 1970 e 1980, ao passo que as duas últimas possuem estudos abrangentes sobre suas gramáticas produzidas a partir dos anos 1990.

- Ainda há muito a descrever acerca da gramática das línguas Apalaí e Kaxuyana.

- Do conjunto de estudos, há aqueles com escopo histórico-comparativo com dados das línguas Apalaí, Kaxuyana e Tiriyó; ausência de estudos envolvendo a língua Wayana.

- Ausência de estudos produzidos no contexto do Complexo do Tumucumaque acerca das línguas Akuriyó e Xikiyana.

- Pouco se sabe sobre as línguas Akuriyó e Xikiyana.

Esse panorama nos faz pensar a tabela apresentada por Moore, Galucio e Gabas-Jr (2008) na qual a língua Kaxuyana é classificada como 1, as línguas Apalaí e Wayana como 2 e a língua Tiriyó é classificada como 3. Mais de uma década após a publicação da tabela, com o panorama aqui apresentado, observamos que o cenário dos estudos linguísticos sofreu pouca alteração. Na mesma tabela, é notável o tratamento de Xikiyana (Shikuyana) como dialeto de Kaxuyana e a ausência de informação relacionada à Akuriyó. Tal ausência nos faz refletir sobre o fato de que "Algumas línguas incluídas na tabela podem já estar extintas, mas são listadas de qualquer maneira, visto que uma busca cuidadosa pode encontrar às vezes falantes restantes em algum lugar”. Segundo os autores, “... se elas não fossem listadas a busca poderia ser abandonada prematuramente". (cf. Moore, Galucio e Gabas-Jr 2008: 5). Nesse sentido, a existência provável de lembrantes da língua Akuriyó indica-nos a necessidade de que a busca a esta língua não seja abandonada prematuramente. 
Estudos relacionados às línguas Xikiyana e Akuriyó devem, antes de tudo, esclarecer às seguintes questões: onde estão os indivíduos Xikiyana e Akuriyó? Que falam ou lembram suas línguas? Qual a real situação de cada uma delas em termos de uso e de vitalidade. No bojo dessas questões, o tratamento de suas gramáticas. No caso da língua Xikiyana, o melhor conhecimento de sua gramática permitiria, inclusive, evidências para justificar seu status de dialeto da língua Kaxuyana, ou mesmo, para negá-lo, já que o compartilhamento de mesmo espaço geográfico não implica necessariamente a perda de uma língua em detrimento de outra.

De um ponto de vista sincrônico, para além do panorama e das questões mencionadas, a observação do quadro revela ausência de estudos que tenham escopo na relação dos aspectos já descritos da gramática com aspectos externos à própria língua. Estudos dessa natureza, quando realizados, terão à sua disposição, dentre outras, relações de contato linguístico que se estabelecem, inclusive com efeitos sobre mudanças linguísticas; questões de identidades; questões de transmissão e de políticas linguísticas; questões semânticas e pragmáticas inerentes ao uso de cada uma das mesmas línguas; questões discursivas. Terão à disposição, ainda, o cenário multilíngue mencionado no início desse artigo, bem como questões de ensino e de aprendizagem dessas línguas no contexto escolar.

A questão do multilinguismo foi tratada por Gomes, Barbosa e Ferreira (2020) como tema ótimo para a sala de aula de língua indígena nas escolas do Complexo do Tumucumaque. Acerca do multilinguismo em si, ao se referirem ao que ocorre na aldeia Bona localizada na Terra Indígena Paru D'Este, os autores retrataram a relação das línguas Apalaí, Tiriyó e Wayana conforme segue: "Numa reunião, por exemplo, se houver Aparaí e Wayana entre os participantes, toda a reunião será realizada na língua Aparai. Se Apalaí, Wayana e Tiriyó presentes, geralmente, dependendo do número de participantes, haverá alguém para fazer a tradução simultânea para Tiriyó" (cf. Gomes, Barbosa e Ferreira 2020: 279). Para além da aldeia Bona, nota-se, por exemplo, que nas aldeias Manau, Maxipurimo e Suisuimymy há falantes da língua Wajãpi (Tupi-Guarani), que, rotineiramente, utilizamse das línguas Tiriyó, Apalaí e Wayana, respectivamente. Em algumas situações cotidianas, todavia, como em conversas por radiofonia com parentes de outras aldeias, utilizam-se da língua Wajãpi. Como consequência desse multilinguismo, os autores indicaram cinco cenários linguísticos distintos que envolvem para além das línguas Wajãpí, Wayana, Apalaí e Tiriyó, o Português Brasileiro.

Cenários como os descritos por Gomes, Barbosa e Ferreira (2020: 279) apontam para a ocorrência, no Complexo do Tumucumaque, de contextos de multilinguismo de pequena escala, nos quais indivíduos interagem falando cada um sua língua, sem a presença necessariamente de uma língua franca ou de contato. Multilinguismo de pequena escala é tratado por Lüpke (2016) como aquele em que práticas comunicativas em sociedades heteroglóssicas não são determinadas estritamente por relações linguísticas hierárquicas, mas por práticas sociais “[...] enraizadas em um contexto geográfico significativo.” (cf. Lüpke 2016: 35). No Complexo do Tumucumaque, como esse multilinguismo de pequena escala ocorre de fato? Como se dão as relações de poder e de identidades entre as línguas envolvidas? Perguntas como estas se constituem relevantes para um melhor entendimento da diversidade linguística do Complexo do Tumucumaque, mas a elas devem ser acrescentadas perguntas que tomem o indivíduo como ponto de partida. Esse indivíduo é a chave para um melhor entendimento do multilinguismo em questão. Como se constitui 
o comportamento multilíngue de pequena escala por esse indivíduo materializado? O multilinguismo de pequena escala que esse indivíduo materializa apresenta semelhanças, por exemplo, com multilinguismos de mesma natureza discutidos por Lüpke (2016) acerca de duas "ecologias linguísticas" atestadas em Senegal e em Camarões (África) e de uma "ecologia linguística" atestadas em Vanuatu (Oceania)?

Embora atestado em todo o mundo, o multilinguismo de pequena escala ainda tem recebido pouca atenção da linguística de contato, de tipologistas, de estudos de multilinguismo (Lüpke 2016). Nesse sentido, o conhecimento daquilo que ocorre no Complexo do Tumucumaque pode contribuir com um melhor entendimento do fenômeno em escala global, mas também regional ao considerarmos a possibilidade de que contextos semelhantes ocorram com outras línguas faladas por populações indígenas amazônicas. Imaginemos a este respeito, os inúmeros cenários de contatos e usos linguísticos gerados pelas populações indígenas que vivem no estado do Pará, as mais de 20 línguas indígenas faladas no estado do Amazonas, as línguas de distintas famílias faladas nos estados de Mato Grosso, Acre, Rondônia, Roraima. Essas populações não falam apenas suas línguas ancestrais, ou adicionam a seu repertorio linguístico apenas o Português Brasileiro. Em virtude das intensas relações de contato, na verdade, as referidas populações conhecem e usam, em algum grau, outras línguas indígenas, gerando, assim como descrito para o Complexo do Tumucumaque, distintos cenários multilíngues.

Um melhor conhecimento dos cenários multilíngues amazônicos importa, inclusive, à Educação Escolar Indígena, que ainda hoje se utiliza do rótulo bilinguismo. Tais cenários nos permitem argumentar em favor de que o rótulo bilinguismo seja abandonado por completo pela Educação Escolar Indígena Amazônica. Consideramos que, em seu lugar, tenhamos o multilinguismo; Educação Escolar Indígena Amazônica Multilíngue. O risco do rótulo bilinguismo é alto nesse contexto de educação, uma vez que implica, quase sempre, uma língua indígena e o Português Brasileiro, cenário que ignora exatamente os contatos, as presenças e os usos de diferentes línguas indígenas por uma mesma sociedade ou por um mesmo indivíduo. A Educação Escolar Indígena Amazônica Multilíngue, portanto, deve, em respeito às historias das populações indígenas por ela atendidas, oporse à ideia de escolas indígenas bilíngues.

A ampliação dos estudos já existentes acerca das línguas do Tumucumaque - o que inclui a possibilidade de comparação com o que ocorre nestas línguas para além das fronteiras do Complexo - bem como a produção de estudos novos capazes de considerar aspectos externos destas línguas, ao tempo em que nos precisam (i) quão diversificada é a região, (ii) formas de potencializar os conhecimentos linguísticos no contexto do ensino e do aprendizado, geram-nos expectativa de ganhos enormes às ciências linguísticas. A este respeito, lembramos aqui de ganhos destas ciências adquiridos a partir do conhecimento de propriedades fonológicas e gramaticais das línguas indígenas brasileiras descritas por Rodrigues (2018). Associados a esses ganhos, os ganhos para a Educação Escolar Indígena Amazônica Multilíngue. Temos, portanto, que um melhor conhecimento das línguas Karíb do Complexo do Tumucumaque, potencialmente, terá efeito sobre as ciências linguísticas e sobre as escolas das populações indígenas.

Um dos aspectos mais promissores relacionados à expectativa de melhor conhecimento das línguas Karíb do Tumucumaque é a presença na Pós-Graduação de indivíduos provenientes destes povos, caso daqueles matriculados no Mestrado em Letras 
do Programa de Pós-Graduação em Letras da Universidade Federal do Amapá (PPGLET/ UNIFAP). Uma língua tem "entranhas" que somente seu falante nativo tem condições de compreendê-las e de explicá-las. São essas "entranhas" que esperamos ver a partir dos estudos realizados pelos indivíduos em questão. Como efeito, inclusive, esperamos ações capazes de potencializar positivamente ações relacionadas ao ensino de cada uma das línguas que constituem o multilinguismo característico da região. Nesse sentido, aquilo que se produz linguisticamente pode, com o devido ajuste, contribuir com o fortalecimento das línguas na escola. Nós acreditamos fortemente que, embora cada um tenha objetivos e métodos próprios, os estudos linguísticos e a sala de aula podem beneficiar-se mutuamente no que confere ao ensino de línguas em contexto indígena. Nessa perspectiva, a sala de aula é vista como um dos lugares onde a língua se fortalece, ao tempo em que reconhece o lugar e o papel de outras línguas.

A ampliação dos estudos linguísticos em seus diferentes escopos tem ainda um elemento essencial, que ultrapassa os limites da Linguística em si: o efeito emocional que tais estudos causam na comunidade de fala. Como linguistas, sabemos do orgulho que as populações sentem ao verem suas línguas objeto de interesse de pesquisadores, sobretudo quando os mesmos falantes atuam de maneira ativa na produção de tais estudos. Quantos de nós vivenciamos contextos em que a comunidade se reunira, como que numa festa, para discutir ou ouvir sobre o trabalho a ser realizado sobre suas línguas? Quantos de nós vivenciamos o orgulho daqueles que participam ativamente do estudo? Trabalhos linguísticos robustos sobre determinada língua, portanto, impactam positivamente a comunidade de fala. A consciência desse impacto é importante no contexto do Complexo do Tumucumaque em que, conforme vimos, a assimetria em termos de quantidade de estudos sobre as línguas é evidente. Particularmente relacionado às línguas Xikiyana e Akuriyó, a ampliação e a produção de estudos linguísticos certamente impactará positivamente a seus falantes ou lembrantes.

Por fim, se a diversidade biológica do Tumucumaque ainda não é completamente conhecida, a ponto de seus pesquisadores a buscarem com a expectativa de melhor conhecer a natureza, a diversidade linguística também ainda não é completamente conhecida, a ponto de buscarmos melhor conhecê-la, o que terá efeitos, inclusive, no melhor conhecimento do cérebro humano e sua relação neurobiológica com a linguagem.

\section{Referências}

Camargo, Eliane (1996). Aspects de la phonologie du wayana. AMERINDIA 21: 115-136.

Camargo, Eliane; Riviere, Hervé (2001-2002). Trois chants de guerre wayana. AMERINDIA 26/27: 87-122.

Camargo, Eliane (2003a). Classes verbais e semântica dos argumentos em um sistema sintático cindido: O exemplo do Wayana (Caribe). In Francesc Queixalós (ed.), Ergatividade na Amazônia II, pp. 83-100. Paris: CNRS-CELIA.

Camargo, Eliane (2003b). Relações sintáticas e semânticas na predicação nominal do Wayana: a oração com cópula. AMERINDIA 28: 133-160. 


\section{GOMES \& FERREIRA - PANORAMA DOS ESTUDOS LINGUÍSTICOS...}

Camargo, Eliane (2008). Operadores aspectuais de estado marcando o nome em wayana (caribe). LIAMES Linguas Indígenas Americanas 8: 85-104. https://doi.org/10.20396/liames.v8i1.147

Camargo, Eliane; Tapinkili; Akajuli; Atajumale; Hernandez, Laurent (2009). Hakëne omijau eitop WajanaPalasisi (Dictionnaire bilíngue Wayana-Français). CELIA/DRAC-GUYANE/TEKUREMAI.

Camargo, Eliane; Wajana, Asiwae (2019). Estratégias da posse em wayana e seu mosaico morfo(fono)lógico. LIAMES - Linguas Indigenas Americanas 19: 1-33. https://doi.org/10.20396/liames.v19i1.8652265

Carlin, Eithne B (1998). Speech community formation: A sociolinguistic profile of the trio of Suriname. New West Indian Guide/ Nieuwe West-Indische Gids 72: 4-42.

Carlin, Eithne B (2004). A grammar of Trio, a Cariban language of Suriname. Duisburg Papers on Research in Language and Culture 55. Frankfurt am Main: Peter Lang.

Carlin, Eithne B (2004). Nominal possession in Trio. Linguistics in the Netherlands 1997: 25-36. https://doi.org/10.1075/avt.14.05car

Carlin, Eithne B (2011). Theticity in Trio (Cariban). International Journal of American Linguistics 77(1): 1-31. https://doi.org/10.1086/657326

Derbyshire, Desmond (1999). Carib. In R. M. W. Dixon; Alexandra Aikhenvald Y. (eds.), The Amazonian Languages, pp. 23-64. Cambridge: Cambridge University Press.

Gildea, Spike (1995). A comparative description of syllable reduction in the Cariban language family. International Journal of American Linguistics 61(1): 62-102. https://doi.org/10.1086/466245

Gildea, Spike (1998). On reconstructing grammar: Comparative Cariban morphosyntax. New York: Oxford University Press.

Gildea, Spike (2012). Linguistic studies in the Cariban family. In Lyle Campbell; Verónica Grondona (eds.), The indigenous languages of South America: A comprehensive guide, pp. 441-494. Berlin.

Gomes, Antonio Almir Silva; Barbosa, Josinete; Ferreira, Iohana (2020). Do bilinguismo ao multilinguismo: um caminho para a escola indígena diferenciada. Caderno de Letras (UFPEL): 36: 257-274.

http://dx.doi.org/10.15210/cdl.v0i36.17365

Gudschinsky, Sarah (1973). Sistemas contrastivos de marcadores de pessoa em duas línguas Carib: Apalaí e Hixkaryána. Série Lingüistica 1: 57-62. Brasília.

Halbmayer, Ernst (2013). Contemporary carib-speaking amerindians: A bibliography of social anthropological and linguistic resources. Curupira Workshop.

Halliday, M. A. K (1967). Notes on transitivity and theme in English. Journal of Linguistics 3: 199-244.

Hayes, Bruce (1995). Metrical stress theory: Principles and case studies. Chicago: University of Chicago Press.

Koehn, Edward (1976). The historical tense in Apalaí narrative. International Journal of American Linguistics 42: 243-52. https://doi.org/10.1086/465419

Koehn, Edward (2009a). The Apalai phrase: prelimirary analysis. Anápolis, Go. Summer Institute of Linguistics. 
Koehn, Edward (2009b). Bound person markers of the Apalai verb phrase: preliminary analysis. Anápolis, Go. Associação Internacional de Linguística.

Koehn, Edward; Koehn, Sally (1971). Fonologia da língua Apalaí. In Sarah Gudschinsky (ed.), Estudos sobre linguas e culturas indigenas, pp. 17-28. Anápolis, GO. Summer Institute of Linguistics.

Koehn, Edward; Koehn, Sally (1986). Apalaí. In Desmond C. Derbyshire; Geoffrey K. Pullum (eds.), Handobook of Amazonian languages 1, pp. 33-127. Berlim: Mouton de Gruyter.

Koehn, Edward; Koehn, Sally (1995). Vocabulário básico, Apalai-Portuguê: Dicionário da Língua Apalaí. Cuiabá. MT. Sociedade Internacional de Linguística.

Koehn, Sally (2009). Apalai verb structure: Prelimirary analysis. Anápolis, GO. Associação Internacional de Linguística, SIL.

Liberman, Mark (1975). The intonational system of English (Dissertação de mestrado). Massachusetts: Massachusetts Institute of Technology.

Liberman, Mark; Prince, Alan (1977). On stress and linguistic rhythm. Linguistic Inquiry 8: 249-336.

Lüpke, Friederike (2016). Uncovering Small-Scale multilingualism. Critical Multilingualism Studies 4(2): 35-74.

Meira, Sérgio (1997). [f], [ñ], e [h]: Fonogênese em Tiriyo (Karíb). Boletim do Museu Paraense Emílio Goeldi: Série Antropologia 13(2): 167-178. http://repositorio.museugoeldi.br/handle/mgoeldi/822

Meira, Sérgio (1998). Rhythmic stress in tiriyó (cariban). International Journal of American Linguistics 64(4): 352-378. https://doi.org/10.1086/466366

Meira, Sérgio (1999). A grammar of Tiriyó (Tese de doutorado em Linguística). Houston, Texas: Rice University.

Meira, Sérgio (2000). A reconstruction of Proto-Taranoan: phonology and morphology (N.A.). München: LINCOM.

Meira, Sérgio (2006). Orações relativas em línguas Karíb. Boletim do Museu Paraense Emílio Goeldi. Ciências Humanas 1(1): 105-121. https://dx.doi.org/10.1590/S1981-81222006000100008

Meira, Sérgio (2016). Mudança sintática em andamento: o caso dos "classificadores genitivos" em línguas caribes. MOARA - Revista Eletrônica do Programa de Pós-Graduação em Letras. http://dx.doi.org/10.18542/moara.v2i43.3840

Migliazza, Ernesto (1965). Notas fonológicas da língua Tiriyó. Boletim do Museu do Índio. Antropologia 29: $1-13$.

http://etnolinguistica.wdfiles.com/local--files/biblio\%3Amigliazza-1965-notas/Migliazza 1965 NotasFonologicasTiriyo.pdf

Moore, Denny; Galucio, Ana Vilacy; Gabas Júnior, Nílson (2008). O desafio de documentar e preservar as línguas amazônicas. Scientific American Brasil (Edição Especial), v. 3: 36-43.

https://amerindias.github.io/referencias/moogalgab08numeroslinguasamazonicas.pdf

Parker, Steve (2001). On the phonemic status of [h] in Tiriyó. International Journal of Linguistics 67(2): 105-118. 


\section{GOMES \& FERREIRA - PANORAMA DOS ESTUdOS LINGUÍSTICOS...}

Rodrigues, Aryon Dall'Igna (1986). Línguas Brasileiras: Para o conhecimento das línguas indígenas. São Paulo: Loyola.

Rodrigues, Aryon Dall'Igna (2018). A originalidade das línguas indígenas brasileiras. Revista Brasileira de Linguística Antropológica 9(1): 187-195. https://doi.org/10.26512/rbla.v9i1.19521

Tavares, Petronila (2005). A grammar of Wayana (Tese de doutorado em Linguística). Houston, Texas: Rice University.

Wallace, Ruth (1970). Notas fonológicas da língua Kaxuyâna. Boletim do Museu Paraense Emílio Goeldi, Antropologia 43: 1-20.

Wallace, Ruth (1976). Harmonia vocálica nos afixos de·posse na língua Kaxuyâna. Revista Brasileira de Linguística 3(2): 42-50.

Wallace, Ruth (1980). Notas verbais da língua Tiriyó. Boletim do Museu do Índio 1(1). 1-14.

Wallace, Ruth (1983). Comparação de afixos de posse em línguas Karíb. Boletim do Museu do Índio 2: 1-31.

Recebido: $12 / 08 / 2020$

Versão revista: 06/10/2020

Aceito: 8/11/2020

Publicado: $16 / 11 / 2020$ 